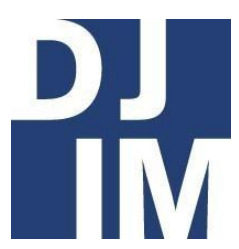

Volume 15

Spring

2019

djim.management.dal.ca |

\title{
Using Tweets as a Measure of Sponsor Engagement: Halifax Pride 2018
}

Nicole Slipp

School of Information Management, Dalhousie University

\begin{abstract}
The following paper considers what researchers can learn from Twitter alone about selected individuals or small groups of users and their sentiments on particular topics. More specifically, it attempts to evaluate the usability of data from Twitter as a measure of sponsor engagement in public events. Given that corporate and government sponsorship of Pride festivals is a pressing ethical concern for LGTBQ communities, this study takes the 2018 Halifax Pride Festival as its case study and performs both quantitative and qualitative analysis of the tweets of sponsors. Analyzing the Twitter data of sponsors of this event reveals some patterns of engagement and identifies the most engaged and informed sponsors.
\end{abstract}

Twitter (www.twitter.com), the popular social media platform with over three hundred and thirty-six million active users (Statista, 2018), is undoubtedly creating data. A decade of research in the social sciences has demonstrated this data's usability as evidence for certain types of studies, particularly the study of large datasets. The present study asks whether Twitter data is useful on a smaller and more local scale. It considers what researchers can learn from Twitter alone about selected individuals or small groups of users and their sentiments on particular topics. This paper specifically explores the feasibility of using Twitter posts (tweets) as an indicator of sponsor engagement: it considers if tweets reveal anything about whether sponsors of a particular event are engaged in a cause beyond monetary support and 
what engaged sponsors of an event might have in common. Due to rising concerns among queer 1 activists over the commercialization of Pride, the question of sponsor engagement in Pride festivals is a particularly relevant one, and the 2018 Halifax Pride Festival is the case study for this paper. Analyzing the Twitter data of sponsors of this event reveals some patterns of engagement and identifies the most engaged and informed sponsors.

\section{The Commercialization of Pride}

The genesis of the Pride festival is generally held to be protests against harassment and demands for queer rights. Many trace the beginning of the modern queer rights movement to the Stonewall riots in New York City on June 28, 1969, for example (Klinefelter, 2011). These sorts of protests turned into organized marches, and those marches turned into annual parades. ${ }^{2}$ The Pride parade has been an essential part of the queer rights movement because it normalizes queer participation in public life and presents queerness as something of which to be proud rather than a shameful secret. In most Western countries today, Pride festivals are celebrations of queer identity and Pride parades attract

${ }^{1}$ Queer is an umbrella term for various sexual and gender identities other than heterosexual and cisgender (where sex assigned at birth matches gender identity). More specific terms, preferred local terms, and acronyms vary, e,g, gay, lesbian, bisexual, transgender, intersex, asexual, two-spirit, LGBT, 2SLBTBQ+, LGTBQ. spectators of all sexual orientations. These events now typically have corporate and government sponsors who donate money or goods.

It is undeniable that queer rights in North America have advanced since the 1960s; however, many activists and theorists point out that only certain queer identities have become somewhat acceptable, and these tend to be those that can fit into existing social structures, for example a monogamous, white, cisgender, middleclass, gay couple. Instead of changing social norms, certain queer people are accepted into them, a process Duggan (2004) critiques and names as homonormativity. As a result of resistance to this process of normalization and assimilation, when corporate and government sponsors get involved in Pride festivals, there is concern about how meaningful their engagement with queer issues is; for example, Utterback (2016) critiques sponsors who simply use a rainbow filter online or put a float in a parade but neglect to grapple with racism or poverty in queer communities and argues, "when corporations support lesbian, gay, bisexual, and transgender rights, they

This paper uses queer as a catchall for the many possibilities of gender and sexual identities.

2 That linear development is of course a simplification, but it is outside the purview of this study to trace the history of Pride in much detail. For more on the subject, see Klinefelter (2011) or James (2018). 
are really capitalizing on another unnamed identity: consumer" (par. 8). Queer people do not want to feel that a company sponsors Pride only because they and their allies now represent a viable market share. The objection to government sponsors is generally for politicians who express support for Pride but who also support policies that negatively impact queer people. This kind of promotion during Pride by politicians or businesses is referred to as pinkwashing (Boon, 2017; Dahl, 2014).

Some, particularly those serving on Pride Festival boards and organizing committees, argue that the commercialization of Pride is not necessarily a bad thing because it signals mainstream acceptance of queer identities (Kushner, 2017), while others argue that if celebrations become too apolitical and commercial, they risk excluding the most vulnerable members of queer communities and endorsing harmful capitalist practices (O'Flynn, 2018; Rand, 2012; Utterback, 2016). Many articles and news stories on the subject of Pride commercialization attempt to provide both perspectives or suggest ways corporatization could be ethical while acknowledging potential problems (Alsop, 2001; Botelho-Urbanski, 2016; Farrar, 2018; Ross, 2016). If there is a path forward for ethical sponsorship, it seems to be through a sponsor's thoughtful engagement with the issues facing queer communities or repeated and meaningful involvement in Pride activities, not just monetary support. The aim of this study will be to see if tweets are a viable way to measure that engagement or involvement.

\section{Halifax Context}

Halifax Pride has not been immune to questions about commercialization or pinkwashing. In 2016, there was major controversy over the inclusion of Size Doesn't Matter, an Israeli tourism group encouraging gay tourism to Tel Aviv, in a Pride community fair (Boon, 2016; Graham, 2016a; Queer Arabs of Halifax, 2016; Segal $\&$ Julia, 2016). The resulting fallout over mishandling of the situation saw community members questioning Halifax Pride's ability to represent marginalized voices, board resignations, and calls for boycotts from queer community groups (Dingwell, 2017b; Graham, 2016b). The following year, Halifax Pride discontinued the community fair, a showcase of sponsors and businesses, in favour of a community market for queer crafters and not-for-profit exhibitors. Adam Reid, Executive Director of Pride, said that Queer Arabs of Halifax's pinkwashing motion had been mishandled at the previous $A G M$, and that the new community market would be more thoughtful about which exhibitors would be included (Dingwell, 2017a).

In 2017, the debate surrounding Halifax Pride was over Prime Minister Justin Trudeau marching in the parade. Critics of the Prime Minister's inclusion in the parade felt that it undermined Pride's stated interest in rebuilding trust with local BIPOC (Black, Indigenous, People of Colour) communities because he, a privileged white 
man, would become the focus of the parade (Boon, 2017). Others argued that it is still meaningful for a Prime Minister to support queer citizens in this way, especially because Trudeau is the first sitting Canadian Prime Minister to do so, so the community should be grateful for his support (Kassam, 2016; King, 2016).

As a demonstration of their commitment to community outreach, Halifax Pride has made changes to its operations since 2016. One such change is the Partner Initiatives Survey, which asks any sponsors and partners to report about what they do to support queer communities apart from sponsoring the Pride festival (Halifax Pride, 2018). Overall, when it comes to sponsorship, people respond best to actual engagement, and the partner survey speaks to this desire to see sponsors who do more for the community than drop-in once a year. Halifax Pride's recent issues with pinkwashing and sponsorship and its relatively small scale make its 2018 Festival an excellent case for a study of how tweets might reflect sponsors' engagement.

\section{Twitter in Social Science Research}

As social media has become part of the daily routine of many individuals and businesses, Twitter has become a valuable source for social science research. As Zimmer and Proferes (2014) put it, "Twitter has emerged as a valuable resource for tapping into the zeitgeist of the internet, its users, and often beyond" (p. 250). Studies of social media can take many forms, including, in broad terms, studies on the behavioural side of social media, on reviews and recommendations, on the integration of social media into workplaces, on social media as a marketing tool, on online communities, on the risks of using social media, on negative stigma towards social media use in the workplace, on social media as value creation, on how users share information during critical events (which is almost always on Twitter), on social media as a path for seeking help, and on comparing traditional media and social media (Kapoor et al., 2017).

The demand for Twitter data in research has resulted in numerous academic publications on methodology (Borra \& Rieder, 2014; Bruns \& Stieglitz, 2013; Jürgens \& Jungherr, 2016; Kapoor et al., 2017; Snelson, 2016; Zimmer \& Proferes, 2014), as well as various free and paid tools to use in data collection, analysis, and visualization. The Social Media Lab at Ryerson University's Social Media Toolkit (2018) is a useful resource for evaluating the functions of over fifty such tools. However, most tools that are free to use are only able to engage with Twitter's API to return results in real-time or from seven days in the past; it also omits an unknown percentage of tweets at random (Borra \& Rieder, 2014). These collect thousands of tweets, which are cleaned of identifying information before being analyzed. In these cases the goal of the study might be to gauge public response to a particular event, or how users from a certain location use 
Twitter, so the identity of the users is not important. While accessing small numbers of tweets, as this study does, is possible, typically Twitter research is more interested in the possibilities of Twitter as a source of insight into large populations and general sentiments on world events. As Bruns and Stieglitz (2013) point out, wide scale generalizations should only be made if the dataset involves at least five thousand users. Jürgens and Jungherr (2016) suggest that, because of the difficulties of working with big data, the best way to collect, store, and analyze Twitter data may be to form cooperative labs of researchers who can each perform one part of the process.

The difficulty with past studies on Twitter methodology is that Twitter changes so rapidly that some methodological practices are no longer applicable. For example, articles written before Twitter updated its terms of service in 2011 and revised how third party services could use its API recommend a service called TwapperKeeper as the best way to collect and export tweet collections; however, after that revision to the terms of service, TwapperKeeper lost most of its functions. Articles written before 2014 might discuss Gnip as a third party reseller of Twitter data, as Puschmann and Burgess (2013) do, but Twitter acquired Gnip in 2014 and absorbed its functions into Twitter provided premium service accounts (Etherington, 2014). There is still value in somewhat older articles on social media research methodology; for example, Kumar,
Morstatter, and Liu's Twitter Data Analytics (2014) instructs researchers on accessing the Twitter API with their own code, and would still be applicable (though likely with some modifications to the source code) for collecting real-time tweets or tracking ongoing hashtags. Articles over two years old will also still be useful if they discuss ethics or use trends, but one must be prepared for any specific technical advice to be out of date.

Many of the ethical issues in using Twitter as a source for research involve the question of whether tweets can be understood as published, public information or not. Although tweets are publically available by default, Puschmann and Burgess (2013) argue that most users do not understand some of the more advanced features of Twitter or its code, and so using their data presents ethical problems because the user does not understand all of what they make public with a tweet. On the other hand, Bruns et al. argue that "publicly visible Twitter messages are guaranteed to have been published to the internet at large, at least technically, and archiving them in the course of research activities is therefore substantially less problematic [than doing the same with other social media types]" (quoted in Zimmer \& Proferes, 2014, p. 256). Breslawski (2014) argues that legally, tweets are not private. Overall, and this may be obvious given the vast number of studies on the subject, researchers in the social sciences have largely agreed that 
social media posts are appropriate as evidence. Of course, there are context dependent procedures to ensure ethical handling of data and legal issues to consider; the Social Feed Manager's (2016) bibliography on research ethics is a helpful place to begin reading in these areas.

Businesses and politicians use their Twitter accounts to make announcements, connect with their customers or constituents, build their brand, and engage with the public (Jacques, 2009; Ioanid \& Scarlat, 2017). Like users in general do (Yoo, Choi, Choi, \& Rho 2014), corporate or political accounts may also tweet to conform to new social expectations or to express their values. Colliander et al. (2017) find that presenting a balance of personal and political tweets can have positive impacts for the individual politician and for their party. Tweeting about Pride festival attendance may therefore be beneficial to politicians in particular because it both expresses a political position and, depending on the content of the tweet, presents the politician as a relatable individual. The reasons that businesses and politicians use Twitter mean that their tweets can be assumed to be intended for mass public consumption, and therefore there are fewer ethical issues at play in collecting and analyzing them.

\section{Methodology}

As discussed above, there are many available free or paid tools for Twitter data analysis. One might also use one's own code or provided code to interact with the Twitter API. For the purposes of this study, the available free services and coding options were not useful because they could only access content generated in real-time or over the past seven days from Twitter and were geared towards retrieving thousands of tweets. After some experimentation, the researcher concluded that the best way to access historical tweets without subscribing to a paid service or to a premium access account to the Twitter API would be to combine the features of Twitter's advanced search (https://twitter.com/search-advanced) and TweetDeck (https://tweetdeck.twitter.com), a once independent dashboard application for tweets acquired by Twitter in 2011 (Empson, 2011). Both require a Twitter user account for access. The researcher used her existing personal account, but for future studies creating a new account might be advisable in order to avoid mixing research with one's personal account and its metadata.

The combination of the two search functions was necessary in order to have both a wider range of search filters and the ability to save results. Twitter advanced search allows for compound searches, with search fields for keywords (all, exact, any, none), hashtags, language, accounts (from, to, mentioning), place, and date. There is an option to save a search, but only its terms, so it is possible the results could change when retrieved on another day. TweetDeck, on the other hand, will save collections of tweets from a search. It has only one search field and allows filtering by 
excluded words, date, location, tweet author, and engagement numbers. However, by conducting a search in the advanced search and then copying the resulting search string into a TweetDeck, one can include the search functions of Twitter advanced search with the saving capabilities of TweetDeck. That is the process used in the searches for this paper. This combined process will only be feasible for small studies like this one; manually collecting and collocating tweets for more users or a larger date range would quickly become unmanageable.

To collect the data for this study it was necessary to decide on specific search terms. The researcher began by looking at the terms Halifax Pride used in its 2018 Pride Guide, adding synonyms as well as the words from queer acronyms to get the most comprehensive results. Two selected groups of search terms, hashtags and keywords, were searched separately each time. The selected hashtags are \#hfxpride, \#hfxpride2018, and \#HappyPride. The selected keywords are pride, LGBT, 2SLGBTQ+, queer, gay, lesbian, bisexual, trans, transgender. The dates for the searches are between July 18 and July 31 , 2018. The official dates of the Halifax Pride Festival were from July 19 until July 29; the selected date range returned tweets just before or after the festivities.

Next, it was necessary to collect the Twitter usernames (handles) of the sponsors of the festival. These are all publically available. The sponsors included both business sponsors and government sponsors. The Pride Guide (Halifax Pride, 2018) contained a full list of sponsors. For the purposes of examining government responses, the researcher selected the accounts of the Mayor, provincial MLAs of Halifax and Dartmouth ridings, provincial leaders of the Liberal, New Democratic, and Progressive Conservative parties, and Members of Parliament for Halifax and Dartmouth. There are two sponsors, one business and one politician, who did not have Twitter accounts (for a full list of sponsors, their Twitter usernames, and their sponsor level see Appendix A). For each sponsor the following information was considered for potential points of analysis: their scope, type, sponsorship level, whether they are for-profit or non-profit, if the Twitter is a local account, and, if applicable, their political affiliation and political position. Sponsorship level is determined by either monetary or in-kind donations from the sponsor. Rainbow sponsors give thirty-five thousand dollars or more; Diamond sponsors give ten thousand dollars or more; Gold sponsors give five thousand dollars or more; Silver sponsors give two thousand five hundred dollars or more; and Friend level sponsors give one thousand dollars or more (A. Reid, personal correspondence, November 28, 2018). All politicians count as local in scope and Twitter account type because they are elected by Haligonians directly or represent a provincial party operating out of Halifax. 
Because of search limitations and a few experimentations, the researcher performed a total of sixteen searches in the process of data collection. As an example of the construction of the search strings (see Appendix B for full record of search strings), the search for hashtag use by government sponsors was:

\section{\#hfxpride OR \#hfxpride2018 OR}

\#HappyPride from:MikeSavageHFX OR from:bmaguirens $O R$ from:GaryBurrill $O R$ from:LisaRobertsHFX OR

from:ChenderMLA OR

from:Keith_W_Colwell OR

from:TimothyHalman $O R$

from:susanleblancMLA OR

from:DarrenFisherNS OR

from:AndyFillmoreHFX OR from:geoffregan since:2018-07-18 until:2018-07-31

Results are grouped into two tweet collections: government sponsors and nongovernment sponsors. For these results, the researcher recorded if the account tweeted about Halifax Pride, how many times they tweeted, and the text of their tweets. The researchers also recorded how many tweets included images, as well as how many tweets included emojis, which emojis were used, and how frequently. A textual analysis using Textalyser (http://textalyser.net) reported on the frequency of top words and top phrases.

\section{Findings}

The retrieval of tweets from fifty-two sponsors of Halifax Pride 2018 resulted in a collection of ninety-three total relevant tweets. Out of fifty-two sponsors, exactly fifty percent, or twenty-six sponsors, tweeted about the 2018 Halifax Pride Festival. The researcher examined these results by a number of factors: sponsorship level, scope, and location of twitter account administration.

There was one sponsor at the Rainbow level, and they did not tweet about the Festival; at the Diamond level there were five sponsors and two tweeted; at the Gold level there were ten sponsors and three tweeted; at the Silver level there were fifteen sponsors and seven tweeted; at the Friends level there were eight sponsors and five tweeted; and at the government level, nine out of thirteen sponsors tweeted (see Figure 1). If a company had a national or international scope, they did not tweet about the festival, while fifty-six percent of those sponsors with a provincial scope tweeted and sixty-seven percent of sponsors with a local scope tweeted (see Figure 2). Sixty-two percent of sponsors with a locally administered twitter account tweeted, while sponsors without a locally administered twitter did not tweet. Fifty percent of sponsors who have a perceived direct connection to queer communities tweeted (three out of six sponsors), and fifty percent of sponsors without a perceived connection to queer communities tweeted (twenty-three out of forty-six sponsors). 


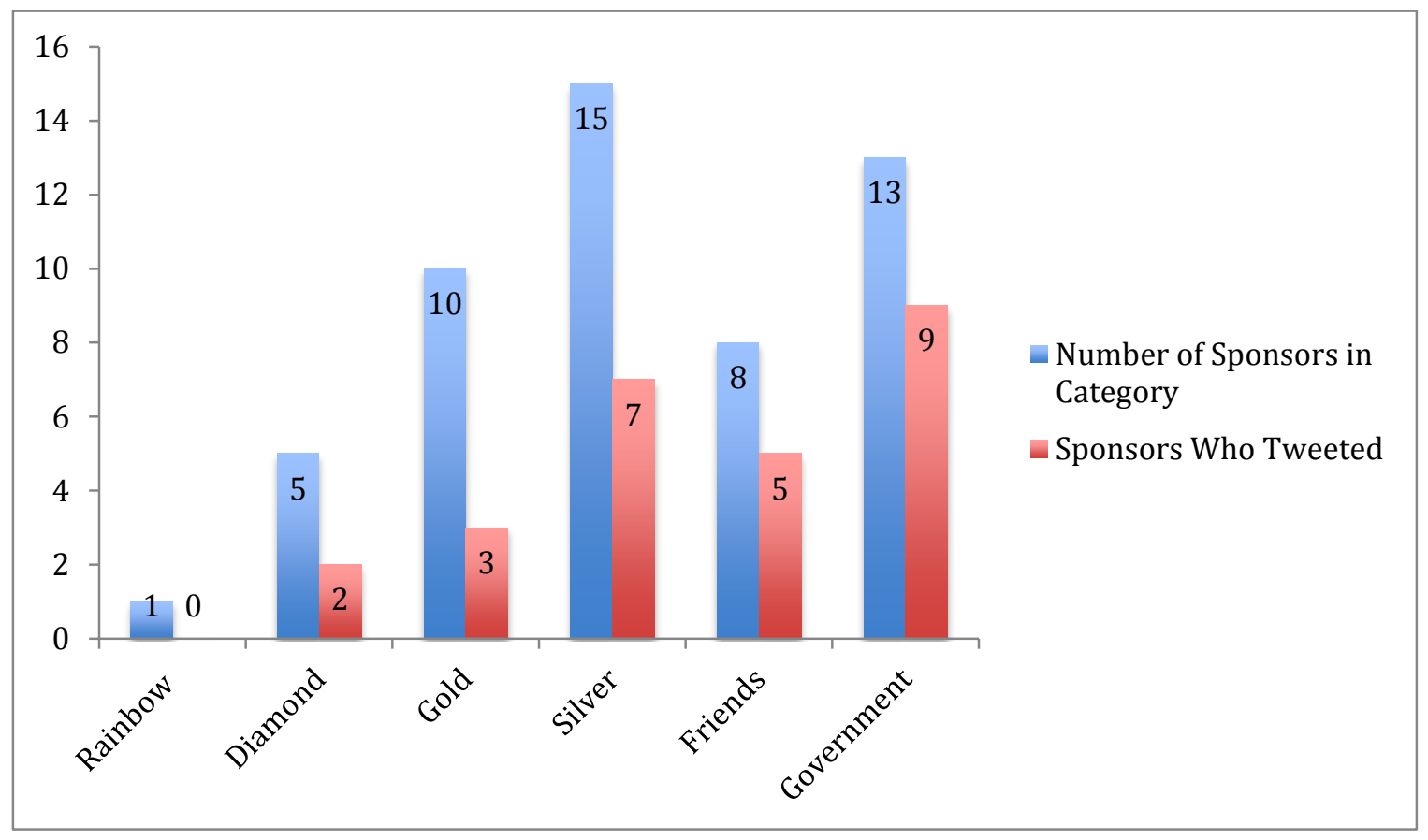

Figure 1 - Tweeters by sponsorship level

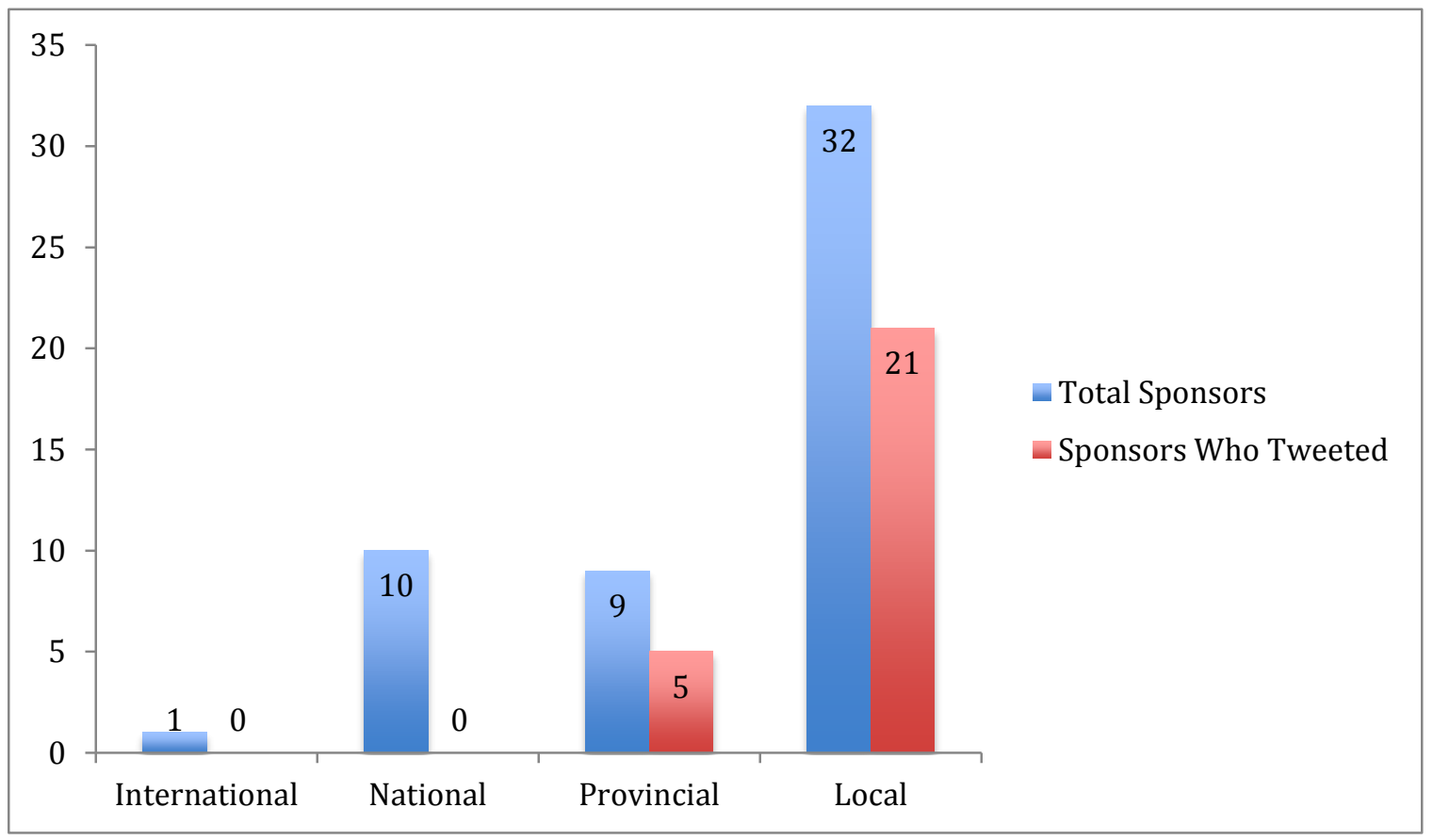

Figure 2 - Sponsors by Scope

Sponsors who did tweet did so at varying frequency (see Figure 3). Halifax Public Libraries tweeted the most, with twelve individual tweets about the festival. Seven sponsors tweeted only once. The average number of tweets from sponsors that tweeted was 3.54 tweets with a mean of 2 tweets. Out of ninety-three tweets, eighty- 
eight contained images. Twenty-nine of the sponsor tweets contained emojis. A Textalyser analysis of the tweets relevant to this study found that the tweets contain 599 unique words and compiled the most commons repeated words and phrases in the tweets. The five most common repeated words in descending order are pride, halifaxpride, parade, you, Halifax.
Leaving out phrases of only prepositions and articles, the ten most repeated two word phrases are happy pride, halifaxpride parade, pride parade, pride Halifax, and see you. The five most repeated three word phrases are happy pride Halifax, the halifaxpride parade, pride happy pride, the pride parade, and parade on Saturday.

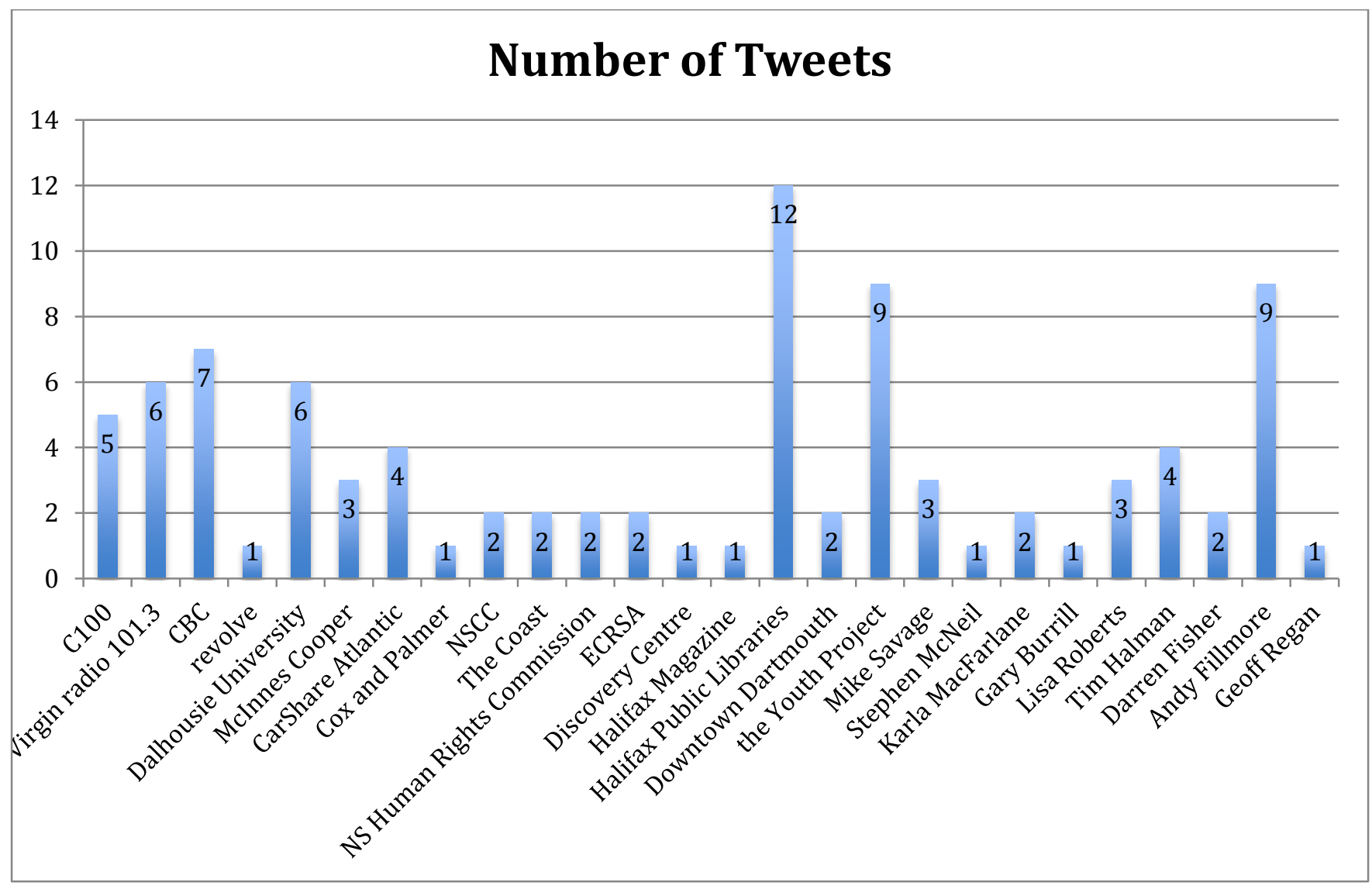

Figure 3 - Number of tweets per sponsor

\section{Discussion}

It is possible to discern some patterns in the tweets of sponsors and to analyze the content of tweets to form conclusions. The researcher came into this study with assumptions about how certain sponsors might tweet, but those assumptions were mostly inaccurate based on the data collected. Though questions of meaningful engagement are hard to measure, a business or government officially sponsoring a Pride festival can be interpreted to mean, at the very least, that that sponsoring entity is not anti-gay. 
Beyond that, the tweets of these sponsors may reveal, again at the least, whether these sponsors participated in Pride events in addition to offering sponsorship, and which events those were. In some cases, discussed more below, the tweets also indicate a level of engagement with queer issues.

\section{Who Tweeted and Who Did Not Tweet?}

It is fairly unsurprising that international and national sponsors did not tweet about the Halifax Pride Festival. These sponsors have nationally administered Twitter accounts that would not be concerned with local events because those events would be irrelevant to many of their followers. In these cases, a lack of engagement on Twitter does not necessarily indicate a lack of engagement with queer communities. TD Canada Trust, for example, is a Rainbow Level sponsor of the Festival, meaning it contributed thirty-five thousand dollars or more to Halifax Pride for the 2018 Festival (A. Reid, personal correspondence, November 28, 2018). TD sponsors over one hundred and sixty Pride festivals across Canada and has been a Pride sponsor since 2004. The company faced pushback from customers over its sponsorship of Pride festivals but continues to offer major support. (Beltrame, 2014; Dagostino, 2010). Its Twitter account tweets during Toronto Pride, the largest festival in Canada, and for Pride month (June) in general, but tweeting about all the smaller festivals it sponsors would be unsustainable for the one central account based out of Toronto.

Using Tweets as a Measure of Sponsor Engagement
The best indicator of whether a sponsor would tweet about the Pride Festival is if the business or person is local in scope, that is, if they are based in Halifax. A strong tie to Halifax was even more important than a perceived affiliation with queerness in the organization. Sixty-seven percent of Halifax based sponsors tweeted. Sponsors with a provincial scope also had a high rate of tweet engagement, at fifty-six percent. Since Halifax is the largest city in Nova Scotia as well as its capital, sponsors with a provincial scope are also likely to be based in Halifax. It is logical that people and businesses operating in Halifax would be more likely to engage with the Festival on Twitter, since it is more likely that they would be directly participating in the events.

A study of Twitter content alone, unfortunately, cannot argue from absence to conclude why sponsors did not tweet. Any business sponsor has chosen to support Pride and it remains unclear why, if they have an active Twitter account, they would not also tweet about the Festival. O'Regan's Kia, for example, is a local to Halifax company that contributed ten thousand dollars or more to the Festival as a Diamond sponsor (A. Reid, personal correspondence, November 28, 2018), but it did not tweet. Future research into Twitter content might ideally also solicit direct feedback from users through surveys or interviews; for example, it would be very useful to know who was responsible for tweeting from each account and how their company generally approaches social 
media use. In the case of engagement for a Pride festival, it would possibly make a difference if a queer person were the one contributing tweet content, for example.

The language of the tweets as revealed by the Textalyser analysis is overwhelmingly positive. The most repeated words mostly involve some variation on "pride" and many other frequently used words introduce concepts of community, joining, and celebration. It would be interesting to see if community members used similarly positive language in their tweets.

\section{Notable Results from Business or Corporate Sponsors}

Some tweet results are notable because they indicate a potential lack of meaningful engagement with queer issues even though they are about celebrating the 2018 Halifax Pride Festival. These tweets are those that include explicit self-promotion or what might be considered advertising content alongside content about Pride. For example, the Halifax radio station C100 FM had two tweets tagging a sponsor of their summer programs, Steele Subaru, thus promoting that company, which is not a Pride sponsor. On the other hand, however, C100FM also linked to a blog post by one of its on air personalities about how she explained Pride to her young daughter, which indicates concern for Pride beyond advertising possibilities.

Tweeting more than once or about multiple events are ways sponsors demonstrated engagement in the Festival. Halifax Public Libraries (HPL) tweeted the most of any sponsor of Halifax Pride in 2018. Several library branches hosted official events for Halifax Pride, and as a result the HPL Twitter feed promotes the widest variety of events from the 2018 Festival, including Drag Queen Storytime and the Halifax Pride Speakers Series. Like many sponsors, they also tweeted about their participation in the Pride parade. Additionally, they posted a list of suggested books with LGBTQ+ themes available in the HPL catalogue. HPL's tweets during Pride indicate that the queer community is part of what happens at the library. Other sponsors whose tweets indicated connections between their business and queer people or communities are the Youth Project (unsurprisingly, because they are a community advocacy group for queer youth) and Dalhousie University, whose tweets highlighted the current work of queer scholars at Dalhousie.

\section{Notable Results from Government Sponsors}

One might have assumed that among politicians, tweeting would fall along party lines, with Progressive Conservative politicians participating less than the Liberals and New Democrats, if at all. However, the data proves this assumption incorrect. The PC leader Karla MacFarlane tweeted twice about Halifax Pride, both times about participating in the Pride parade. Timothy Halman, the Progressive Conservative and MLA for Dartmouth East, tweeted four times about Pride; all his tweets concerned the Pride parade as well, including one about bringing his children to the parade. One of the NDP MLAs for 
Halifax, Susan Leblanc, did not tweet about Pride. However, she did not tweet at all during the month of July, so this data may not be significant. On the other hand, Liberal MLA for Halifax Atlantic Brendan Maguire tweeted frequently (seventeen times) during the Halifax Pride Festival, but never about Pride. One can reasonably infer from this data that Mr. Maguire does not support queer communities in Halifax, since he would have been invited to participate in events and declined to do so, and since the Liberals had a float in the parade, which he would also have declined to participate in.

All MPs for Halifax tweeted about the Pride Festival, and two in particular tweeted in ways that could indicate meaningful engagement. Andy Fillmore, Halifax MP and member of the Liberal party, tweeted the most of any politician about the 2018 Festival. Based on his tweets, he attended the Pride flag raising, a Pride Shabbat dinner, the Pride parade, and a parade after-party. He also posted a video with the federal advisor on LGBTQ2 in which they discuss current government initiatives to benefit queer communities in Canada, including extending protections granted by the Canada Human Rights Act to include trans people. Mr. Fillmore's tweets indicate a higher than average level of engagement with the Pride Festival. Darren Fisher, Liberal MP for Dartmouth-Cole Harbour, tweeted only twice about the Festival. However, one of his tweets included a short video in which Mr. Fisher talks about the first Pride parade in Halifax and the threats of homophobic violence people faced for participating then, and a call to "rededicate ourselves to a future where every single one of us, no matter our gender expression, gender identity, or orientation is free to be who they are" (Fisher, 2018). This acknowledgement of past and current difficulties for queer communities is notable among other mostly celebratory tweets.

Mere participation in Pride, if not backed up by policy and action, would be classified as pinkwashing. More research into the specific voting records and other background of these politicians would be necessary to gauge their engagement with queer communities more accurately. It might be useful to see if politicians tweet about queer issues at any other time of year, since the celebration of Pride is much easier to deal with than engaging with negative or challenging queer community issues. While it is difficult to tell from tweets alone if a politician supports queer communities in all of their actions, when a politician tweets many times during Pride or includes content acknowledging the hardships queer communities face, it is at least indicative of an attempt at meaningful engagement on their part.

\section{Limitations}

The greatest limitation to this study is its scope. Collecting more tweets, from a variety of locations over more years would yield more data to analyze; this data would be especially interesting as a measure of 
the evolution of engagement with Pride festivals. Future work might also do comparison between the tweets of sponsors and the tweets of community members, which could provide direct evidence of community response to sponsor engagement. It would also be an advantage to have software to collect and analyze the tweets, rather than doing so manually. Another limitation to this study is a lack of analysis of the pictures included in tweets from sponsors; photo attachments might give more insight into, at the least, a sponsor's level of enthusiasm for Pride events. Similarly, a future study might consider the significance of emoji use in these kinds of tweets.

\section{Conclusions}

Tweets provide an incomplete picture on sponsor engagement, but they do provide some insight, particularly into enthusiasm levels. When a sponsor tweets about an event it indicates that their engagement extends beyond financial support. Merely tweeting may not be enough to indicate meaningful engagement, however, especially in the case of Pride festivals, where there is a danger of sponsors practicing pinkwashing. If a sponsor tweets many times or, again in the case of Pride festivals, includes content beyond celebration that acknowledges the struggles of queer communities, then that sponsor demonstrates at least an attempt at meaningful engagement. Further studies should consider tweet content alongside other measures of sponsors' commitment to community events as well as in comparison to the tweets of community members.

\section{References}

Alsop, R. (2001, June 22). Corporate sponsorships at gay pride parades alienate some activists-dissenters say events now put sales ahead of protesting; staging a "gay shame" rally. The Wall Street Journal. Retrieved from https://search.proquest.com/ docview/398817745/abstract/402A 05CBEF24731PQ/1

Beltrame, J. (2014, June 25). TD Bank's diversity a point of literal pride for CEO. The Huffington Post. Retrieved from http://www.huffingtonpost.ca/201 4/06/25/td-bankdiversity_n_5530269.html

Boon, J. (2016, October 2). Halifax Pride draws ire over proposed pinkwashing motion. The Coast. Retrieved from https://www.thecoast.ca/RealityBit es/archives/2016/10/02/ halifaxpride-draws-ire-over-proposedpinkwashing-motion

Boon, J. (2017, July 18). Trudeau pinkwashing Pride parade. The Coast. Retrieved from https://www.thecoast.ca/RealityBit es/archives/2017/07/18/trudeaupinkwashing-pride-parade 
Borra, E., \& Rieder, B. (2014). Programmed method: Developing a toolset for capturing and analyzing tweets. Aslib Journal of Information Management, 66(3), 262-278. doi: 10.1108/AJIM-09-2013-0094

Botelho-Urbanski. (2016, June 28). LGBT Night March decries Pride's corporate sponsorship. The Toronto Star. Retrieved from https://www.thestar.com/news/gta /2016/06/28/lgbt-night-marchdecries-prides-corporatesponsorship.html

Breslawski, T. M. (2014). Privacy in social media: To tweet or not to tweet? Touro Law Review, 29(4), 12831304. Retrieved from http://digitalcommons.tourolaw.ed u/ lawreview/vol29/iss4/16.

Bruns, A., \& Stieglitz, S. (2013). Towards more systematic Twitter analysis: Metrics for tweeting activities. International Journal of Social Research Methodology, 16(2), 91108. doi: 10.1080/13645579.2012.756095

Colliander, J., Marder, B., Lid Falkman, L. Madestam, J., Modig, E., \& Sagfossen, S. (2017). The social media balancing act: Testing the use of a balanced selfpresentation strategy for politicians using Twitter. Computers in Human Behavior,
74, 277-285. doi: 10.1016/j.chb.2017.04.042

Dagostino, S. (2010, April 12). Public pressure from pride sponsorship nothing new: TD Bank. Daily Xtra. Retrieved from https://www.dailyxtra.com/publicpressure-from-pride-sponsorshipnothing-new-td-bank-10649

Dahl, S. (2014, August 26). The rise of pride marketing and the curse of pink washing. The Conversation. Retrieved from http://theconversation.com/therise-of-pride-marketing-and-thecurse-of-pink-washing-30925

Dingwell, R. (2017a, June 2). Halifax Pride addresses pinkwashing by discontinuing community fair. The Coast. Retrieved from https://www.thecoast.ca/RealityBit es/ archives/2017/06/02/ halifaxpride-addresses-pinkwashing-bydiscontinuing-community-fair

Dingwell, R. (2017b, July 19). South House offers alternative pride event. The Coast. Retrieved from https://www.thecoast.ca/RealityBit es/archives/2017/07/19/southhouse-offers-alternative-prideevent

Duggan, L. (2004). The twilight of equality? Neoliberalism, cultural politics, and the attack on democracy. Boston, MA: Beacon Press. 
Empson, R. (2011, May 23). Twitter buys

TweetDeck for 40 million.

TechCrunch. Retreived from https://techcrunch.com/2011/05/2

3/twitter-buys-tweetdeck-for-40-

million/

Etherington, D. (2014, April 15). Twitter acquires longtime partner and social data analytics provider Gnip. TechCrunch. Retrieved from https://techcrunch.com/2014/04/1 5/ twitter-acquires-longtimepartner-and-social-data-analyticsprovider-gnip/

Farrar, M. (2018, July 22). The problem with corporatization \& LGBTQ pride. The Proud Diplomat.

Retrieved from http://www.theprouddiplomat.com /facts/2018/7/22/the-problemwith-corporatization-lgbtq-pride

Fisher, D. [DarrenFisherNS]. (2018, July 18). Happy Pride Week! Will I see you at the Parade on Saturday? @HalifaxPride \#Pride2018 VIDEO. Retrieved from https://twitter.com/ DarrenFisherNS/status/101957016 8085798912

Graham, A. (2016a, October 6). Pinkwashing motion voted down at Halifax Pride AGM. The Coast. Retrieved from https://www.thecoast.ca/RealityBit es/archives/2016/10/06/ pinkwashing-motion-voted-downat-halifax-pride-agm

Graham, A. (2016b, December 29). Halifax Pride's new director, uncertain direction. The Coast. Retrieved from

https://www.thecoast.ca/RealityBit es/archives/2016/12/29/halifaxprides-new-director-uncertaindirection

Halifax Pride. (2018). Halifax Pride Guide. Halifax, NS: revolve Branding.

Ioanid, A., \& Scarlat, C. (2017). Factors influencing social networks use for business: Twitter and YouTube analysis. Procedia Engineering, 181, 977-983. doi: 10.1016/j.proeng.2017.02.496

Jacques, A. (2009). Get shorty: The business applications for Twitter. Public Relations Tactics, 16(7), 1010. Retrieved from http://web.a.ebscohost.com/ehost/ detail /detail?vid=0\&sid =d41a16e9d1b6-430e-8b0da3aad0bbef94\%40sdc-vsessmgr02\&bdata $=$ JnNpdGU9ZW hvc3QtbGI2ZQ\%3d\%3d\#db=bth\& $\mathrm{AN}=44573677$

James, M. K. (2018). Gay and lesbian movement: An overview. In S. Bronner (Ed.), Encyclopedia of American studies. MD: Johns Hopkins University Press. 
Jürgens, P., \& Jungherr, A. (2016). A tutorial for using Twitter data in the Social Sciences: Data collection, preparation, and analysis. SSRN. Retrieved from http://dx.doi.org/10.2139/ssrn.271 0146

Kapoor, K. K., Tamilmani, K., Rana, N. P., Patil, P., Dwivedi, Y. K., \& Nerur, S. (2018). Advances in social media research: Past, present and future. Information Systems Frontiers, 20(3), 531-558. doi: 10.1007/s10796-017-9810-y

Kassam, A. (2016, July 4). Syrian refugee marches beside Justin Trudeau in Canadian Pride parade. The Guardian. Retrieved from https://www.theguardian.com/worl d/ 2016/jul/04/syrian-refugeemarches-beside-justin-trudeaucanada-pride-parade

King, R.L. (2016, July 3). Trudeau makes history in Toronto Pride parade. The Toronto Star. Retrieved from https://www.thestar.com/news/gta /2016/07/03/toronto-prideparade-kicks-off.html

Klinefelter, K. (2011). History of gay/lesbian rights movement. In A. J. Andrea, World history encyclopedia. Santa Barbara, CA: ABC-CLIO.

Kumar, S., Morstatter, F. \& Liu, H. (2014). Twitter data analytics. New York: Springer.
Kushner, H. (2017, August 29). Corporate pride isn't totally a bad thing, here's why. Entity. Retrieved from https://www.entitymag.com/comm ercialization-of-pride/

O'Flynn, B. (2018, August 7). Is it possible to escape the commercialization of pride? Them. Retrieved from https://www.them.us/story/pridecommercialization

Puschmann, C. \& Burgess, J. (2013). The politics of Twitter data. SSRN. Retrieved from https://papers.ssrn.com/abstract=2 206225

Queer Arabs of Halifax. (2016, October 13). Halifax Pride stands at a crossroads. The Coast. Retrieved from https://www.thecoast.ca/halifax/ha lifax-pride-stands-at-a crossroads $/$ Content?oid $=5725787$

Rand, E. J. (2012). Gay pride and its queer discontents: ACT UP and the political deployment of affect. Quarterly Journal of Speech, 98 (1), 75-80. doi: 10.1080/00335630.2011.638665

Ross, I. (2016, August 11). The business of gay pride. The Financial Times. Retrieved from https://www.ft.com/content/22820 7c6-5f46-11e6-ae3f77baadeb1c93 
Segal, R. \& Julia, M. (2016, October 2).

We're young Jews and we support Queer Arabs of Halifax. The Coast.

Retrieved from

https://www.thecoast.ca/halifax/we re-young-jews-and-we-support-

queer-arabs-of-

halifax/Content?oid $=5703440$

Snelson, C.L. (2016). Qualitative and mixed methods social media research: $A$ review of the literature.

International Journal of Qualitative Methods, 15(1), 1-15. doi

10.1177/1609406915624574

Social Feed Manager. (2017). Legal and ethical issues of social media collecting: Annotated bibliography. Retrieved from https://gwulibraries.github.io/sfmui/resources/annotatedbibliography

Social Media Lab at Ryerson University. (2018). Social media research toolkit. Social media data stewardship. Retrieved from http://socialmediadata.org/socialmedia-research-toolkit/
Statista. (2018). Number of monthly active international Twitter users from 1st quarter 2010 to 3rd quarter 2018 (in millions). Retrieved from https://www.statista.com/ statistics/274565/monthly-activeinternational-twitter-users/

Utterback, A. (2016, June 30). The capitalist appropriation of gay pride. The Establishment. Retrieved from https://medium.com/theestablishment/the-capitalistappropriation-of-gay-pride$150 f \mathrm{fc} 6111326$

Yoo, J., Choi, S., Choi, M. \& Rho, J. (2014). Why people use Twitter: social conformity and social value perspectives. Online Information Review, 38(2), 265-283. doi: 10.1108/OIR-11-2012-0210

Zimmer, M., \& John Proferes, N. (2014). A topology of Twitter research: Disciplines, methods, and ethics. Aslib Journal of Information Management, 66(3), 250-261. doi:10.1108/AJIM-09-2013-0083 


\section{Appendix A}

List of Sponsors, Their Twitter Usernames, Sponsorship Levels, and Scope of Operations

\begin{tabular}{|c|c|c|}
\hline Business/Sponsor Name & Twitter Username @ & Sponsorship Level \\
\hline TD Canada Trust & TD_Canada & Rainbow \\
\hline Tweed & TweedInc & Diamond \\
\hline C100 & C100FM & Diamond \\
\hline Virgin radio 101.3 & VirginRadioHali & Diamond \\
\hline CIBC & cibc & Diamond \\
\hline O'Regan's Kia & ORegansKiaHFX & Diamond \\
\hline Stoli & Stoli & Gold \\
\hline Host Often & HostOften & Gold \\
\hline Winners & LifeatTJXCanada & Gold \\
\hline CBC & CBCNS & Gold \\
\hline Marriott Halifax Harbourfront & HalifaxMarriott & Gold \\
\hline Delta Hotels Halifax & Deltas_in_HFX & Gold \\
\hline Admiral Jobs & AdmiralJobsHFX & Gold \\
\hline revolve & revolvebranding & Gold \\
\hline Atlantic Superstore & SuperstoreNS & Gold \\
\hline Dalhousie University & Dalnews & Gold \\
\hline MicMac Mall & micmacmall & Silver \\
\hline McInnes Cooper & mcinnescooper & Silver \\
\hline CarShare Atlantic & carshare_atl & Silver \\
\hline Jazz & aircanada & Silver \\
\hline NS Teacher's Union & NSTeachersUnion & Silver \\
\hline Cox and Palmer & CoxandPalmer & Silver \\
\hline NSCC & NSCCnews & Silver \\
\hline The Coast & TwitCoast & Silver \\
\hline NS Human Rights Commission & NSHumanRights & Silver \\
\hline Enterprise & halifax_erac & Silver \\
\hline Deloitte & DeloitteCanada & Silver \\
\hline Murphy's the Cable Wharf & MurphysHalifax & Silver \\
\hline OutTVGo & OUTtv & Silver \\
\hline
\end{tabular}




\begin{tabular}{|l|l|l|}
\hline Xtra & dailyxtra & Silver \\
\hline ECRSA & TheECRSA & Silver \\
\hline pride Health & HealthNS & Friend \\
\hline Wacky's Flooring & WackysFlooring & Friend \\
\hline Discovery Centre & DiscoveryCntr & Friend \\
\hline Halifax Magazine & HalifaxMagazine & Friend \\
\hline Indigo Parking & GroupIndigo_ & Friend \\
\hline Halifax Public Libraries & hfxpublib & Friend \\
\hline Downtown Dartmouth & DT_Dartmouth & Friend \\
\hline the Youth Project & YouthProject_NS & Friend \\
\hline MacFarland's Industrial & no twitter account & Friend \\
\hline Mike Savage & MikeSavageHFX & Government \\
\hline Stephen McNeil & StephenMcNeil & Government \\
\hline Karla MacFarlane & karla_macf_pc & Government \\
\hline Gary Burrill & GaryBurrill & Government \\
\hline Brendan Maguire & bmaguirens & Government \\
\hline Lisa Roberts & LisaRobertsHFX & Government \\
\hline Claudia Chender & ChenderMLA & Government \\
\hline Keith Colwell & Keith_W_Colwell & Government \\
\hline Tim Halman & TimothyHalman & Government \\
\hline Susan Leblanc & susanleblancMLA & Government \\
\hline Lena Metlege & no Twitter account & Government \\
\hline Darren Fisher & DarrenFisherNS & Government \\
\hline Andy Fillmore & AndyFillmoreHFX & Government \\
\hline Geoff Regan & geoffregan & Government \\
\hline
\end{tabular}




\section{Appendix B}

\section{Search Strings Used in Data Collection}

pride OR LGBT OR 2SLGBTQ+ OR queer OR gay OR lesbian OR bisexual OR trans OR transgender from:MikeSavageHFX OR from:bmaguirens OR from:GaryBurrill OR from:LisaRobertsHFX OR from:ChenderMLA OR from:Keith_W_Colwell OR from:TimothyHalman OR from:susanleblancMLA OR from:DarrenFisherNS OR from:AndyFillmoreHFX OR from:geoffregan since:2018-07-18 until:2018-07-31 \#hfxpride OR \#hfxpride2018 OR \#HappyPride from:MikeSavageHFX OR from:bmaguirens OR from:GaryBurrill OR from:LisaRobertsHFX OR from:ChenderMLA OR from:Keith_W_Colwell OR from:TimothyHalman OR from:susanleblancMLA OR from:DarrenFisherNS OR from:AndyFillmoreHFX OR from:geoffregan since:2018-07-18 until:2018-07-31

from:bmaguirens OR from:Keith_W_Colwell OR from:susanleblancMLA OR from:geoffregan since:2018-07-18 until:2018-07-31

Pride OR LGBT OR 2SLGBTQ+ OR queer OR gay OR lesbian OR bisexual OR trans OR transgender from:TD_Canada OR from:TweedInc OR from:C100FM OR from:VirginRadioHali OR from:cibc OR from:ORegansKiaHFX since:2018-07-18 until:2018-07-31

\#hfxpride OR \#hfxpride2018 OR \#HappyPride from:TD_Canada OR from:TweedInc OR from:C100FM OR from:VirginRadioHali OR from:cibc OR from:ORegansKiaHFX since:2018-07-18 until:2018-07-31

Pride OR LGBT OR 2SLGBTQ+ OR queer OR gay OR lesbian OR bisexual OR trans OR transgender from:Stoli OR from:HostOften OR from:LifeatTJXCanada OR from:CBCNS OR from:HalifaxMarriott OR from:Deltas_in_HFX since:2018-07-18 until:2018-07-31

\#hfxpride OR \#hfxpride2018 OR \#HappyPride from:Stoli OR from:HostOften OR from:LifeatTJXCanada OR from:CBCNS OR from:HalifaxMarriott OR from:Deltas_in_HFX since:2018-07-18 until:2018-07-31

Pride OR LGBT OR 2SLGBTQ+ OR queer OR gay OR lesbian OR bisexual OR trans OR transgender from:AdmiralJobsHFX OR from:revolvebranding OR from:SuperstoreNS OR from:Dalnews OR from:micmacmall OR from:mcinnescooper since:2018-07-18 until:2018-07-31 
\#hfxpride OR \#hfxpride2018 OR \#HappyPride from:AdmiralJobsHFX OR from:revolvebranding OR from:SuperstoreNS OR from:Dalnews OR from:micmacmall OR from:mcinnescooper since:2018-07-18 until:2018-07-31

Pride OR LGBT OR 2SLGBTQ+ OR queer OR gay OR lesbian OR bisexual OR trans OR transgender from:carshare_atl OR from:aircanada OR from:NSTeachersUnion OR from:CoxandPalmer OR from:NSCCnews OR from:TwitCoast since:2018-07-18 until:2018-07-31

\#hfxpride OR \#hfxpride2018 OR \#HappyPride from:carshare_atl OR from:aircanada OR from:NSTeachersUnion OR from:CoxandPalmer OR from:NSCCnews OR from:TwitCoast since:2018-07-18 until:2018-07-31 Pride OR LGBT OR 2SLGBTQ+ OR queer OR gay OR lesbian OR bisexual OR trans OR transgender from:NSHumanRights OR from:halifax_erac OR from:DeloitteCanada OR from:MurphysHalifax OR from:TheECRSA OR from:NSHealth since:2018-07-18 until:2018-07-31

\#hfxpride OR \#hfxpride2018 OR \#HappyPride from:NSHumanRights OR from:halifax_erac OR from:DeloitteCanada OR from:MurphysHalifax OR from:TheECRSA OR from:NSHealth since:2018-07-18 until:2018-07-31

Pride OR LGBT OR 2SLGBTQ+ OR queer OR gay OR lesbian OR bisexual OR trans OR transgender from:dailyxtra OR from:OUTtv OR from:WackysFlooring OR from:DiscoveryCntr OR from:GroupIndigo_ OR from:HalifaxMagazine OR from:hfxpublib OR from:DT_Dartmouth OR from:YouthProject_NS since:2018-07-18 until:2018-07-31 \#hfxpride OR \#hfxpride2018 OR \#HappyPride from:dailyxtra OR from:OUTtv OR from:WackysFlooring OR from:DiscoveryCntr OR from:GroupIndigo_OR from:HalifaxMagazine OR from:hfxpublib OR from:DT_Dartmouth OR from:YouthProject_NS since:2018-07-18 until:2018-07-31 